Check for updates

The BMJ

Cite this as: $B M J 2021 ; 375: n 3107$ http://dx.doi.org/10.1136/bmj.n3107 Published: 17 December 2021

\title{
Covid-19: Need for social restrictions will gradually shrink over time, says England's CMO
}

\section{Gareth lacobucci}

The development of polyvalent vaccines and new antivirals should lessen the need for social restrictions from around the middle of 2023 , England's chief medical officer has told MPs.

Giving evidence to the House of Commons Health and Social Care Committee on 16 December, Chris Whitty said that although the UK may need intermittent social restrictions against covid-19 over the next 18 months, future medical advances should provide the "heavy lifting" against new variants.

He said, "If I project forward, I would anticipate in a number of years, possibly 18 months, possibly slightly less, possibly slightly more, we will have polyvalent vaccines which will cover a much wider range [of variants]. And we will probably have several antivirals ... and a variety of other countermeasures that mean that the great majority, and probably almost all, of the heavy lifting when we get a new variant-unless it is extremely different-can be met by medical means."

He added, “So I don't see this as a kind of 'we're going to have to do this [social restrictions] repeatedly every few months' situation. I think the risks will gradually decrease over time; it's incremental."

However, Whitty said that for now some social restrictions may be necessary to tackle variants such as omicron that show some partial escape from vaccines and could overwhelm the NHS if left unchecked. He said, “We've come from a place where we had absolutely nothing [in terms of medical interventions], so everything had to be done by social distancing and all the disruptive things that went with that right at the beginning. Where we are at the moment is kind of in a transition period. A very large amount of it can be done by [vaccines], and this is why the boosters are so absolutely essential, but we're not quite in the rather safer haven I expect we will have in a couple of years' time.”

Whitty repeated his message he first made in a Downing Street briefing on 15 December that it would be sensible for the public to prioritise social interactions that really mattered to them in the run up to Christmas.

His comments sparked a political row after the Conservative MP Joy Morrissey, the parliamentary private secretary to the justice secretary, Dominic Raab, criticised Whitty on social media. Morrissey wrote, "Perhaps the unelected covid public health spokesperson should defer to what our ELECTED members of parliament and the prime minister have decided.
"I know it's difficult to remember but that's how democracy works. This is not a public health socialist state."

In a letter to Raab, Steve Reed, Labour's shadow secretary of state for justice, called the comments "unacceptable and dangerous" and said Morrissey should be sacked unless she apologised.

In his evidence to MPs Whitty also predicted that daily admissions to hospital in England could exceed the previous high of 4500 in the next few weeks because of the steepness of the rise in omicron cases. But he said that increased protection given by vaccines could result in shorter stays in hospital and fewer patients being admitted to intensive care.

"What we shouldn't assume is that, if we got the same number going in the front door, that necessarily translates into the same numbers in hospital in an ICU at some point in the new year," he said. 